\title{
Non-Communicable Chronic Diseases and Structural Indicators in an Epidemiological Transition Country
}

\author{
Natalia Romero-Sandoval1,2* (), S. Ramiro Canelos ${ }^{3}$, Héctor Javier Sánchez-Pérez 2,4 (i), \\ Ricardo Romero5, Fernando Cornejo6, Miguel Martín-Mateo',2,7 (i)
}

${ }^{1}$ Escuela de Medicina, Facultad de Ciencias Médicas, de la Salud y de la Vida, Universidad Internacional del Ecuador, Quito, Ecuador

${ }^{2}$ Grups de Reserca d'Amèrica i Àfrica Llatines-GRAAL, Cerdanyola del Vallés, España

${ }^{3}$ Facultad de Ciencias Administrativas, Universidad Internacional del Ecuador, Quito, Ecuador

${ }^{4}$ El Colegio de la Frontera Sur-ECOSUR, San Cristóbal de Las Casas, Chiapas, México

${ }^{5}$ Instituto Geográfico Militar, Seniergues E4-676 y Gral. Telmo Paz y Miño, Quito, Ecuador

${ }^{6}$ Facultad de Medicina, Universidad Tecnológica Equinoccial, Bourgeois, Quito, Ecuador

${ }^{7}$ Unidad de Bioestadística, Facultad de Medicina, Universidad Autónoma de Barcelona, Cerdanyola del Vallés, Barcelona, Spain Email: *nromero@uide.edu.ec, rcanelos@uide.edu.ec, hsanchez@ecosur.mx, ricardo.vinromero@gmail.com, fichiec@gmail.com, España.miquel.martin@uab.cat

How to cite this paper: Romero-Sandoval, N., Canelos, S.R., Sánchez-Pérez, H.J., Romero, R., Cornejo, F. and Martín-Mateo, M. (2020) Non-Communicable Chronic Diseases and Structural Indicators in an Epidemiological Transition Country. Open Journal of Epidemiology, 10, 32-42. https://doi.org/10.4236/ojepi.2020.101003

Received: September 22, 2019

Accepted: December 13, 2019

Published: December 16, 2019

Copyright $\odot 2020$ by author(s) and Scientific Research Publishing Inc. This work is licensed under the Creative Commons Attribution International License (CC BY 4.0).

http://creativecommons.org/licenses/by/4.0/

\section{(c) (i) Open Access}

\begin{abstract}
Objective: To determine associations between standardized prevalence ratios of Metabolic Syndrome (MS), High Blood Pressure (HBP), and Obesity $(\mathrm{O})$ with structural factors in ecuadorian population aged 20 to 59 . Methods: An ecological study was conducted through data from the Ecuador's National Health and Nutrition Survey 2013-2014, and National Census. Standardized prevalence ratio (SPR) variability was analyzed with Poisson multiple regression models (adjusted Relative Risk). Results: The SPR variability for the three diseases was associated with non-affiliation to social security, and inversely related to lower urbanization. HBP and O were associated with functional illiteracy and higher rates of primary care physicians/1000 inhabitants. HBP and MS were related to poor housing. Conclusions: Policies of non-communicable chronic diseases control in ecological transition countries need to take structural variations into account.
\end{abstract}

\section{Keywords}

Chronic Illness, Social Inequality, Statistical Analysis, Policy Process, Ecuador 


\section{Introduction}

Non-communicable chronic diseases (NCDs) are recognized as one of the leading causes of disability, premature morbidity and high mortality, [1] they are of long duration and generally slow progression. Cardiovascular diseases, cancer, chronic respiratory diseases and diabetes are responsible for $82 \%$ of NCD-related deaths, worldwide: more than $40 \%$ of these deaths were premature (before age 70 years), and $82 \%$ of these premature deaths occurred in low- and middle-income countries in 2012 [2].

An understanding of the multifactorial complexity of NCDs in each geographical setting, allows us to describe the behaviour of epidemiological indicators to guide to the design of prevention and control activities, in both developed and underdeveloped countries [3].

Ecuador is a middle-income Latin American country, which is in a process of transition: demographic (aging population), epidemiological (presence of communicable and non-communicable diseases) and socioeconomic (urbanization of poverty); [4] its 26 administrative territorial units (ATU) exhibit differences in terms of the proportions of sex, ethnic origin, proportion of urbanization, financial status, cultural and behavioural attributes [5] [6].

In 2012, 9.8\% of the Ecuadorian population aged 20 to 59 years and economically active had hypertension, $4.5 \%$ had diabetes, $39.1 \%$ metabolic syndrome, and $62.8 \%$ were overweight/obese [7].

Variations in structural factors could contribute to increase prevalence rates of NCDs and to a lack of social cohesion and they impede sustainable human and economic development in a region [8] [9].

Given this situation, we proposed to analyse the distribution of standardized prevalence ratios of metabolic syndrome (MS), high blood pressure (HBP) and obesity $(\mathrm{O})$ and its association with structural factors, in the population aged 20 to 59 years, aggregated in 26 ATUs, through an ecological study, considering the same criteria used by the Government of Ecuador for the distribution of health resources in the country. The standardized prevalence ratios express the difference between the observed rate and the expected rate, taking overall Ecuador figures as reference.

\section{Materials and Methods}

\subsection{Study Design}

Ecological study which used the 26 ATU defined officially in Ecuador. The ecological unit was the ATU, administrative ecological units which is used by the government of Ecuador for any distributive and political decision in the country. The criteria used are the same as the census of Ecuador [6]. In this case, population of these ecological units was truncated to consider people between 20 to 59 years old. The exposures and outcomes of inhabitants were aggregated to these units treated as indicators of the final considered population [10]. 


\subsection{Data Source and Acquisition}

We used data from three sources: 1) The National Health and Nutrition Survey 2011-2013 (ENSANUT 2011-2013); [7] 2) The 2010 Population and Housing Census (CPV2010); [6] and, 3) The 2012 Survey of Health Resources and Activities (ERS2012) [11].

1) ENSANUT 2011-2013. This survey collected information about NCDs, as well as physical activity, nutritional status, foods eaten, and access to food complement and prophylactic supplement programs. It used a stratified, multistage, area probability survey design, sampling the population aged under 60 years of age. Subsequent weighting of the data permitted calculation of national estimates. This survey was sponsored by the National Planning Secretariat, the Ministry of Public Health and National Institute of Statistics and Census (INEC). The survey was administered through confidential, anonymous, face-to-face interviews in the home by trained interviewers. The database is publicly accessible [12]. For more details see the related technical report [7].

From this survey, and for the population aged 20 to 59 years (10960 participants), we obtained the global prevalence rates in Ecuador of MS, HBP and O, and their specific prevalence rates by age-group and sex, as well as the global and specific prevalence rates of these conditions for each ATU.

Subjects were considered to have MS if their waist circumference was greater than or equal to $90 \mathrm{~cm}$ for men, and $80 \mathrm{~cm}$ for women, and they presented at least two of the following indicators: triglyceride level over $150 \mathrm{mg} / \mathrm{dl}$; high density lipoproteins under $40 \mathrm{mg} / \mathrm{dl}$ for men, under $50 \mathrm{mg} / \mathrm{dl}$ for women; blood pressure over 130/80 mmHg; plasma glucose over $100 \mathrm{mg} / \mathrm{dl}$ [13]. They were considered to have HBP if their systolic blood pressure was $140 \mathrm{mmHg}$ or higher, and/or diastolic blood pressure was $90 \mathrm{mmHg}$ or over [14]. Subjects were considered Obese if their body mass index was 30 or higher [15].

2) CPV2010: This consisted of a multi-objective national survey conducted by the INEC, designed to provide information about demographic, social and economic indicators in Ecuador. The census was applied throughout the country, the questionnaire was administered directly to the head of the household, on a day when all members had to be at home for the purposes of the survey. The CPV2010 was structured in various components, of which we have used two: persons (CPV2010_p) and housing (CPV2010_h).

We obtained the following social variables from the CPV2010_p: urbanization status (Urb), defined as residing in a basic geo-statistical territory with a settlement of grouped dwellings; functionally illiterate (three or fewer years of basic education) (FIll); not affiliated to Social Security (NoSSec).

Information relating to the following structural variables was obtained from the CPV2010_h: no access to drinking water, sewage system, electricity supply, or rubbish collection system, presence of overcrowding (three or more persons sleeping in same room), these being summarised for each household as an indicator called "Structural deficiencies" (SDef), when that household presented two 
or more such deficiencies.

3) ERS2012. This survey collects information about health personnel, teams and activities carried out during 2012, in all health-related establishments, whether they involve internment of patients or not. From this survey we obtained the rate of primary care physicians/1000 inhabitants (PCP).

\subsection{Creation of Ecological Indicators}

1) Truncated population pyramids in five-year age groups were elaborated for each ATU.

2) Aggregation of the structural indicators, explained above, allowed us to generate indicators, in the form of percentages of individuals and households, respectively, for each ATU. These indicators were grouped into three categories $\left(\mathrm{Q}_{1}=\right.$ first quartile, $\mathrm{Q}_{2-3}=$ interquartile range, $\mathrm{Q}_{4}=$ fourth quartile $)$, where the first quartile corresponded to the lowest values of the indicator.

\subsection{Data Analysis}

Prevalence rates in each ATU were standardized using the indirect method (standardized prevalence ratio SPR), taking as reference the specific rates for Ecuador as a whole. Standardized prevalence ratio variability of each disease was analysed using Poisson multiple regression models (adjusted Relative Risk, RR), taking the first quartile of the indicator value as the reference. All analyses were conducted using SPSS v.24.

With the aim of providing an overview of the joint presence of the indicators studied, the map shows the model from the weighting of indexes of each of them. The map was elaborated using Analytic Hierarchy Process. For the weighted model we used values of the Pearson correlations [16] between the indicators.

\section{Results}

\subsection{General Characteristics of the Factors Analyzed}

Table 1 presents the distribution of the factors analysed. The value of Urb ranged between $16.9 \%$ and $67.7 \%$. The proportion of FIll ranged between $1.7 \%$ and $11.0 \%$. In $50 \%$ of the ATU the NoSSec indicator values ranged between 73.0 and $79.5 \%$ of the inhabitants. The proportion of dwellings with structural deficiencies ranged between $35.9 \%$ and $84.3 \%$. The values of PCP were between 43.0 and 1025.0/1000 inhabitants.

For all indicators the best situation, i.e. falling within the first quartile, was observed to be concentrated in four ATU. Figure 1 shows the joint weighted presence of the five correlated indicators.

Correlations between the indicators studied fluctuated between 0.302 and 0.619 ( $\mathrm{p}<0.01$ in all cases). Persons not having any social security had a higher tendency to present SDef in their homes, FIll, and the lowest proportion of Urb. PCP was not significantly correlated with any of the other indicators. 
Table 1. Variations of geographical and structural factors, Ecuador.

\begin{tabular}{cccc}
\hline & Minimum value & Interquartile range & Maximum value \\
\hline Population & 14,901 & 193,064 & $1,310,800$ \\
Area $\left(\mathrm{km}^{2}\right)$ & 3146.9 & 6851.9 & $29,628.7$ \\
Population density & 1.4 & 33.4 & 320.6 \\
Urbanization status (\%) & 16.9 & 49.4 & 67.7 \\
Functionally illiterate (\%) & 1.7 & 5.5 & 11.0 \\
Not affiliated to Social Security (\%) & 64.3 & 77.4 & 82.8 \\
Structural deficiencies in housing (\%) & 35.9 & 62.4 & 84.3 \\
Primary care physicians/1000 inhabitants & 43.0 & 255.0 & 1025.0 \\
\hline
\end{tabular}

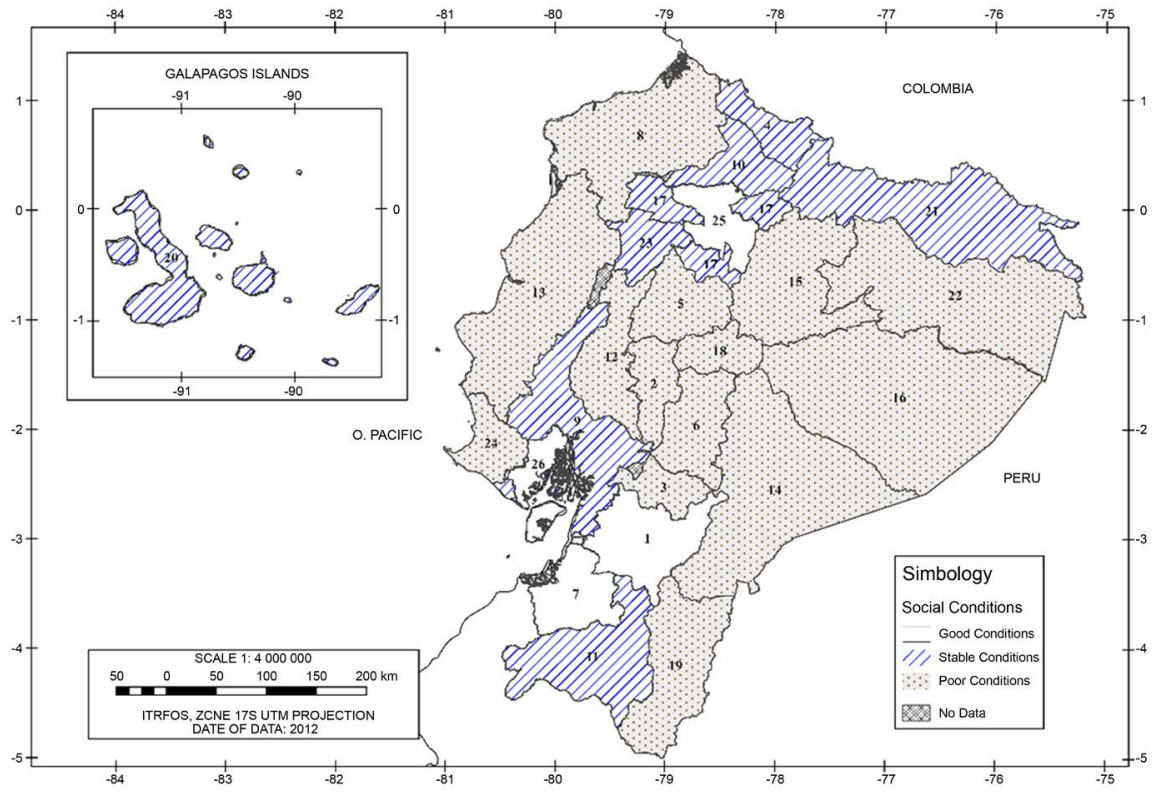

Figure 1. The numbers correspond to each administrative territorial units (ATU).

\subsection{Prevalence Rate and Standardized Prevalence Ratios of MS, HBP and 0}

Table 2 shows the variations of the prevalence rates/1000 inhabitants and SPR for the three diseases studied. Correlations between the SPR of the three diseases studied fluctuate between 0.59 and 0.64 ( $\mathrm{p}$ value $<0.01$ in all cases).

\subsection{Connection between SPR and Indicators}

Table 3 presents the results of fitting Poisson models for the SPR of each disease studied. In the three diseases we observe a significant increase in the SPR associated to higher percentages of non-affiliation to social security, whereas the SPR decreased as the proportion of urbanization decreased. We also observed that the SPR for HBP and O increased when the proportion of functional illiteracy increased. Similarly, the SPR of MS and HBP increased when the proportion of household structural deficiencies increased. 
Table 2. Variation of prevalence rate and standardized prevalence ratio of metabolic syndrome, high blood pressure, obesity.

\begin{tabular}{cccc}
\hline & Minimum value & Interquartile range & Maximum value \\
\hline PR -Metabolic syndrome & 57.7 & 98.8 & 341.9 \\
SPR -Metabolic syndrome & 0.70 & 0.95 & 1.21 \\
PR -High Blood Pressure & 9.0 & 37.8 & 111.8 \\
SPR -High Blood Pressure & 0.24 & 0.82 & 1.58 \\
PR -Obesity & 113.8 & 193.0 & 451.0 \\
SPR -Obesity & 0.58 & 0.99 & 1.27 \\
\hline
\end{tabular}

PR Prevalence rate per 1000 population; SPR Standardized Prevalence Ratio.

Table 3. Connection between standardized prevalence ratios of metabolic syndrome, high blood pressure, obesity and structural indicators.

\begin{tabular}{|c|c|c|c|c|c|c|c|}
\hline \multirow[b]{2}{*}{ Factor } & \multirow[b]{2}{*}{ Category } & \multicolumn{2}{|c|}{ Model = Metabolic Syndrome } & \multicolumn{2}{|c|}{ Model $=$ High Blood Pressure } & \multicolumn{2}{|c|}{ Model $=$ Obesity } \\
\hline & & $\begin{array}{c}\text { Crude RR } \\
(95 \% \text { CI })\end{array}$ & $\begin{array}{l}\text { Adjusted RR } \\
(95 \% \mathrm{CI})\end{array}$ & $\begin{array}{c}\text { Crude RR } \\
(95 \% \text { CI })\end{array}$ & $\begin{array}{l}\text { Adjusted RR } \\
(95 \% \mathrm{CI})\end{array}$ & $\begin{array}{c}\text { Crude RR } \\
(95 \% \mathrm{CI})\end{array}$ & $\begin{array}{c}\text { Adjusted RR } \\
(95 \% \mathrm{CI})\end{array}$ \\
\hline \multirow[t]{3}{*}{ Urb } & Highest* & & & & & & \\
\hline & Intermediate & $\begin{array}{c}0.959 \\
(0.955-0.963)\end{array}$ & $\begin{array}{c}1.025 \\
(1.016-1.035)\end{array}$ & $\begin{array}{c}1.036 \\
(1.029-1.043)\end{array}$ & $\begin{array}{c}0.893 \\
(0.883-0.904)\end{array}$ & $\begin{array}{c}0.888 \\
(0.886-0.891)\end{array}$ & $\begin{array}{c}0.860 \\
(0.855-0.865)\end{array}$ \\
\hline & Lowest & $\begin{array}{c}0.853 \\
(0.846-0.859\end{array}$ & $\begin{array}{c}0.960 \\
(0.949-0.971)\end{array}$ & $\begin{array}{c}0.535 \\
(0.527-0.542)\end{array}$ & $\begin{array}{c}0.523 \\
(0.519-0.541)\end{array}$ & $\begin{array}{c}0.642 \\
(0.737-0.646)\end{array}$ & $\begin{array}{c}0.641 \\
(0.635-0.647)\end{array}$ \\
\hline \multirow[t]{3}{*}{ FIll } & Lowest ${ }^{*}$ & & & & & & \\
\hline & Intermediate & $\begin{array}{c}0.981 \\
(0.976-0.985)\end{array}$ & $\begin{array}{c}0.860 \\
(0.850-0.870)\end{array}$ & $\begin{array}{c}1.133 \\
(1.123-1.143)\end{array}$ & $\begin{array}{c}1.156 \\
(1.136-1.177)\end{array}$ & $\begin{array}{c}0.882 \\
(0.878-0.886)\end{array}$ & $\begin{array}{c}1.070 \\
(1.062-1.079)\end{array}$ \\
\hline & Highest & $\begin{array}{c}0.998 \\
(0.993-1.003)\end{array}$ & $\begin{array}{c}0.885 \\
(0.874-0.897)\end{array}$ & $\begin{array}{c}1.332 \\
(1.322-1.341)\end{array}$ & $\begin{array}{c}1.219 \\
(1.193-1.246)\end{array}$ & $\begin{array}{c}0.903 \\
(0.900-0.906)\end{array}$ & $\begin{array}{c}1.084 \\
(1.073-1.095)\end{array}$ \\
\hline \multirow[t]{3}{*}{ noSSec } & Lowest* & & & & & & \\
\hline & Intermediate & $\begin{array}{c}1.038 \\
(1.034-1.042)\end{array}$ & $\begin{array}{c}1.124 \\
(1.113-1.135)\end{array}$ & $\begin{array}{c}1.259 \\
(1.250-1.269)\end{array}$ & $\begin{array}{c}1.142 \\
(1.128-1.155)\end{array}$ & $\begin{array}{c}0.940 \\
(0.937-0.943)\end{array}$ & $\begin{array}{c}1.037 \\
(1.031-1.043)\end{array}$ \\
\hline & Highest & $\begin{array}{c}1.114 \\
(1.106-1.122)\end{array}$ & $\begin{array}{c}1.220 \\
(1.208-1.232)\end{array}$ & $\begin{array}{c}1.494 \\
(1.481-1.507)\end{array}$ & $\begin{array}{c}1.412 \\
(1.395-1.428)\end{array}$ & $\begin{array}{c}1.009 \\
(1.005-1.014)\end{array}$ & $\begin{array}{c}1.072 \\
(1.066-1.078)\end{array}$ \\
\hline \multirow[t]{3}{*}{ SDef } & Lowest ${ }^{*}$ & & & & & & \\
\hline & Intermediate & $\begin{array}{c}0.902 \\
(0.897-0.906)\end{array}$ & $\begin{array}{c}0.969 \\
(0.959-0.980)\end{array}$ & $\begin{array}{c}0.863 \\
(0.856-0.870)\end{array}$ & $\begin{array}{c}0.857 \\
(0.843-0.870)\end{array}$ & $\begin{array}{c}0.800 \\
(0.797-0.803)\end{array}$ & $\begin{array}{c}0.895 \\
(0.888-0.901)\end{array}$ \\
\hline & Highest & $\begin{array}{c}1.107 \\
(1.102-1.113)\end{array}$ & $\begin{array}{c}1.157 \\
(1.144-1.170)\end{array}$ & $\begin{array}{c}1.614 \\
(1.602-1.626)\end{array}$ & $\begin{array}{c}1.301 \\
(1.281-1.322)\end{array}$ & $\begin{array}{c}0.985 \\
(0.981-0.988)\end{array}$ & $\begin{array}{c}0.990 \\
(0.953-0.968)\end{array}$ \\
\hline \multirow[t]{3}{*}{ PCP } & Lowest ${ }^{*}$ & & & & & & \\
\hline & Intermediate & $\begin{array}{c}1.001 \\
(0.997-1.005)\end{array}$ & $\begin{array}{c}0.929 \\
(0.922-0.923)\end{array}$ & $\begin{array}{c}0.762 \\
(0.751-0.773)\end{array}$ & $\begin{array}{c}0.915 \\
(0.907-0.923)\end{array}$ & $\begin{array}{c}0.946 \\
(0.939-0.952)\end{array}$ & $\begin{array}{c}1.095 \\
(1.091-1.100)\end{array}$ \\
\hline & Highest & $\begin{array}{c}0.887 \\
(0.868-0.887)\end{array}$ & $\begin{array}{c}0.909 \\
(0.898-0.921)\end{array}$ & $\begin{array}{c}0.955 \\
(0.948-0.961)\end{array}$ & $\begin{array}{c}1.058 \\
(1.040-1.078)\end{array}$ & $\begin{array}{c}1.075 \\
(1.071-1.078)\end{array}$ & $\begin{array}{c}1.112 \\
(1.103-1.121)\end{array}$ \\
\hline
\end{tabular}

*: Reference category; RR: Relative risk; Urb: Urbanization status; noSSec: No social security; FIll: Functional illiteracy; SDef: Structural deficiencies of the dwelling; PCP: Primary care physicians /1000 inhabitants. 
On the other hand, the highest presence of PCP/1000 inhabitants is associated with an increase of $11.2 \%$ in the rate of $\mathrm{O}$ in its highest category, and $5.8 \%$ in the rate of HBP, compared to baseline, while the rate of MS fell $9.1 \%$.

\section{Discussion}

Through this ecological study analysed information on a set of structural factors associated to the standardized prevalence ratios of metabolic syndrome, high blood pressure and obesity, as data aggregated over the territorial units of a country in epidemiological transition. This ecological research was carried out to examine the factors and associations at the group level, we do not intend to make inferences at the individual level [10] [17]. This study is the first to be conducted in Ecuador in this field, making use of different governmental sources of publicly accessible information.

The results have shown that in the population aged 20 to 59 years, an important proportion of which is economically active, greater rates of individuals not affiliated to security social were related to higher SPR for all three diseases. We also found that those ATU with higher proportions of FIll had more people with HBP and O. This association is not surprising since the same trend is shown in multiple studies, the explanation being the difficulty in understanding behavioural patterns by illiterate patients, which in turn belong to the weakest layers economically and therefore follow inappropriate nutritional guidelines [18] [19].

Data from a worldwide health survey, 2002 to 2004, show that people with the lowest levels of wealth and education had higher prevalence of certain NCDs such as angina, arthritis, asthma, depression and comorbidities, despite the fact that no solid data was available from the low- and medium-income countries [20].

In the ATU with the lowest proportions of urbanization, the number of patients observed is lower than if the problem were to behave as in the rest of the country. The phenomenon of rapid urbanization is associated with changes in behaviour which increase the risk of NCDs [21]. One study derived from ENSANUT found that the double burden of undernutrition and excess weight in the Ecuadorian population is a serious problem, especially in women and children [22].

Our results are cause for reflection about the boundaries and meanings of rural compared to urban. One anthropological study in the Andean area showed that identifying rural with "traditional", and urban as synonymous with "modernity", can no longer be upheld, since the operational parameters are not necessarily in opposition. Rural areas have close ties with urban life, while urban, popular, culture is the result of the gradual integration of indigenous, colonial elements which have become modified, and elements that are modern, from western culture [23].

Another study in Ecuador showed that a higher level of urbanization, defined as improvements in urban infrastructures, public services, changes in social 
structures and lifestyle, and population growth, among other factors, was associated with a higher prevalence of asthma in the population aged 7 to 15 years old [24].

One ecological study in 18 European countries showed that urbanization of poverty and the rise in unhealthy lifestyles produced drastic effects on life expectancy of elderly adults, due to non-communicable chronic diseases [25].

The number of doctors per thousand inhabitants and the SPR of the diseases, did not always present the negative association which might be expected, since it is possible that efforts to confer health resources on those areas with the highest prevalence of the diseases analysed, would only achieve a reduction in the very long term, through a reduction of the incidence.

The overall objective of reducing by $25 \%$ the probability of dying by non-communicable diseases among persons aged 30 to 70 by 2025, [26] which has joined the Government of Ecuador, is based on an understanding of the influence of social and health inequalities, as well as an understanding of biological and behavioural sciences [27] [28].

Loss of productivity, especially among individuals aged between 20 and 59 years, due to disability or premature deaths associated to NCDs act as important barriers to poverty reduction and sustainable development [29].

The results of this study, which show a higher proportion of people with the three diseases studied, in the geographical areas with increased urbanization, but at the same time, with a greater proportion of FIll, NoSSec, and SDef, should be considered to strengthen the actions of prevention and control of NCDs as an integrated and collective intervention, and considering territorial differences.

It cannot be determined empirically if the differences found between the ATU are the product of a different level of implementation of the country's health policies, before the information is collected, therefore, these data are initial hypotheses that generate further analyses that, with little funding available, could improve the situation.

\section{Limitations}

This study has the following limitations: 1) this was an ecological study and therefore does not permit estimation of causal connections, merely associations between the presence of social/structural indicators and prevalence rates; 2) ENSANUT data refer to a point in time two years after the census, but in any case, no other national level data are available; 3 ) the age range studied for the three diseases corresponds to that for which ENSANUT data are available, however the burden of chronic diseases of this type is greater in people aged over 65 years, as has been reported by various epidemiological studies, [30] [31] 4) as no updated census data are available, it is not possible to present an association coinciding better in terms of time; 5) as is logical, an appreciable co linearity between indicators impedes considering the true effects of their joint presence in a principal effects model, due to the relatively small number of ecological units, 
which makes it difficult to include interaction terms in the model.

\section{Conclusions}

The most important significance of this study is to be the first analysis of chronic non-communicable diseases distribution, ecological unit-level related to socioeconomic indicators, that due to their involvement in health and their economic consequences in the short and medium term should arouse the interest of the country's health authorities in order to dedicate resources to its prevention and consideration for the destination of health resources. This analysis would contribute to the baseline level to establish between unit differences prior to the application of intervention measures.

The connection between a set of the structural indicators, and the regional rates of MS, HBP and $\mathrm{O}$ in geographical administrative units identified those areas in which urgent action is required, not only in terms of the diseases, but also in terms of the structural indicators and review of health policy planning.

\section{Availability of Data and Material}

The datasets analyzed during the current study are available in the INEC (http://www.ecuadorencifras.gob.ec/institucional/home/) repository.

\section{Authors' Contributions}

NR, HS and MM carried out the study, participated in the design of the study and wrote the manuscript. MM, RR did the statistical analyses. RC and FC contributed to study design and drafting. All authors read and approved the final manuscript.

\section{Conflicts of Interest}

The authors declared no conflict of interests.

\section{References}

[1] Adams, R. (2015) Prevention Is Better than Cure: Tackling Non-Communicable Diseases in Developing Countries by Focusing on Prevention. Perspectives in Public Health, 135, 121-122. https://doi.org/10.1177/1757913915580929

[2] WHO (2014) Global Status Report on Noncommunicable Diseases 2014. https://www.cabdirect.org/cabdirect/abstract/20153093363

[3] Benziger, C.P., Roth, G.A. and Moran, A.E. (2016) The Global Burden of Disease Study and the Preventable Burden of NCD. Global Heart, 11, 393-397. https://doi.org/10.1016/j.gheart.2016.10.024

[4] Sapag, J.C. and Kawachi, I. (2007) Social Capital and Health Promotion in Latin America. Revista de Saúde Pública, 41, 139-149. https://doi.org/10.1590/S0034-89102007000100019

[5] Secretaría Nacional de Planificación y Desarrollo-SENPLADES (2015) Sistema Nacional de Información.

[6] Instituto Nacional de Estadísticas y Censo (2010) Censo de Población y Vivienda 
2010. https://www.ecuadorencifras.gob.ec/censo-de-poblacion-y-vivienda/

[7] Encuesta Nacional de Salud y Nutrición-ENSANUT. Ministerio de Salud Pública. http://www.salud.gob.ec/encuesta-nacional-de-salud-y-nutricion-ensanut/

[8] Borrell, C. (2015) Epidemiología Social: La persona, la población y los determinantes sociales de la salud. Cuadernos de la Fundación Dr. Antonio Esteve, No. 32, 33-37.

[9] Marmot, M. (2013) Universal Health Coverage and Social Determinants of Health. The Lancet, 382, 1227-1228. https://doi.org/10.1016/S0140-6736(13)61791-2

[10] Neumark, Y. (2017) What Can Ecological Studies Tell Us about Death? Israel Journal of Health Policy Research, 6, 52. https://doi.org/10.1186/s13584-017-0176-x

[11] Instituto Nacional de Censos de Ecuador. Anuario de Recursos y Actividades de Salud.

http://www.ecuadorencifras.gob.ec/anuario-de-recursos-y-actividades-de-salud/

[12] Freire, W.B., Belmont, P., López-Cevallos, D.F. and Waters, W.F. (2015) Ecuador's National Health and Nutrition Survey: Objectives, Design, and Methods. Annals of Epidemiology, 25, 877-878. https://doi.org/10.1016/j.annepidem.2015.08.009

[13] Zimmet, P., Alberti, G. and Shaw, J. (2005) A New IDF Worldwide Definition of the Metabolic Syndrome: Of the Metabolic Syndrome: The Rationale and the Results. Diabetes Voice, 50, 31-33.

[14] Chobanian, A.V., Bakris, G.L., Black, H.R., Cushman, W.C., Green, L.A., Izzo, J.L., et al. (2003) Seventh Report of the Joint National Committee on Prevention, Detection, Evaluation, and Treatment of High Blood Pressure. Hypertension, 42, 1206-1252. https://doi.org/10.1161/01.HYP.0000107251.49515.c2

[15] Cole, T.J. and Lobstein, T. (2012) Extended International (IOTF) Body Mass Index Cut-Offs for Thinness, Overweight and Obesity. Pediatric Obesity, 7, 284-294.

https://doi.org/10.1111/j.2047-6310.2012.00064.x

[16] Saaty, R.W. (1987) The Analytic Hierarchy Process-What It Is and How It Is Used. Mathematical Modelling, 9, 161-176. https://doi.org/10.1016/0270-0255(87)90473-8

[17] Richardson, S., Stücker, I. and Hémon, D. (1987) Comparison of Relative Risks Obtained in Ecological and Individual Studies: Some Methodological Considerations. International Journal of Epidemiology, 16, 111-120. https://doi.org/10.1093/ije/16.1.111

[18] Maldonado-Reyes, F.J., Vázquez-Martínez, V.H., Loera-Morales, I.I., Jesús, I. and Ortega-Padrón, M. (2016) Prevalence of Therapeutic Adherence in Hypertensive Patients with the Use of the Martin-Bayarre-Grau Questionnaire. Atención Familiar, 23, 48-52. https://doi.org/10.22201/facmed.14058871p.2016.2.54784

[19] Luna-Breceda, U., Haro-Vázquez del, R., Uriostegui-Espíritu, L.C., Barajas-Gómez, T.J. and Rosas-Navarro, D.A. (2017) Level of Adherence in Patients with Hypertension: Experience in a Family Medicine Unit in Zapopan Jalisco, Mexico. Atención Familiar, 24, 116-120. https://doi.org/10.1016/j.af.2017.07.004

[20] Sommer, I., Griebler, U., Mahlknecht, P., Thaler, K., Bouskill, K., Gartlehner, G., et al. (2015) Socioeconomic Inequalities in Non-Communicable Diseases and Their Risk Factors: An Overview of Systematic Reviews. BMC Public Health, 15, 914. http://www.ncbi.nlm.nih.gov/pmc/articles/PMC4575459/ https://doi.org/10.1186/s12889-015-2227-y

[21] Oni, T. and Unwin, N. (2015) Why the Communicable/Non-Communicable Disease Dichotomy Is Problematic for Public Health Control Strategies: Implications of Multimorbidity for Health Systems in an Era of Health Transition. International 
Health, 7, 390-399. https://doi.org/10.1093/inthealth/ihv040

[22] Freire, W.B., Silva-Jaramillo, K.M., Ramírez-Luzuriaga, M.J., Belmont, P. and Waters, W.F. (2014) The Double Burden of Undernutrition and Excess Body Weight in Ecuador. The American Journal of Clinical Nutrition, 100, 1636S-1643S. https://doi.org/10.3945/ajcn.114.083766

[23] Kingman, E. and Solo de Zaldívar, V.B. (2016) Las fronteras arbitrarias y difusas entre lo urbano-moderno y lo rural-tradicional en los Andes-Buscar con Google. Journal of Latin American \& Caribbean Anthropology, 22, 235-253.

https://www.google.com/search?q=Las+fronteras+arbitrarias $+\mathrm{y}+$ difusas+entre+lo+ urba-

no-moderno $+y+l o+$ rural-tradicional $+e n+l o s+$ Andes\&ie $=u t f-8 \& o e=u t f-8 \& c l i e n t=$ fir efox-b-ab\&gfe $r d=c r \& e i=c A K p V 5 T r H s n j 8 A f 6 y I H o C A$

[24] Rodriguez, A., Vaca, M., Oviedo, G., Erazo, S., Chico, M.E., Teles, C., et al. (2011) Urbanisation Is Associated with Prevalence of Childhood Asthma in Diverse, Small Rural Communities in Ecuador. Thorax, 66, 1043-1050. https://doi.org/10.1136/thoraxjnl-2011-200225

[25] Ribeiro, A.I., Krainski, E.T., Carvalho, M.S. and de Pina M.F. (2016) Where Do People Live Longer and Shorter Lives? An Ecological Study of Old-Age Survival across 4404 Small Areas from 18 European Countries. Journal of Epidemiology \& Community Health, 70, 561-568. https://doi.org/10.1136/jech-2015-206827

[26] Baker, P., Friel, S., Kay, A., Baum, F., Strazdins, L. and Mackean, T. (2017) What Enables and Constrains the Inclusion of the Social Determinants of Health Inequities in Government Policy Agendas? A Narrative Review. International Journal of Health Policy and Management, 7, 101-111. https://doi.org/10.15171/ijhpm.2017.130

[27] Marmot, M. and Allen, J. (2015) Health Priorities and the Social Determinants of Health. Eastern Mediterranean Health Journal, 21, 671-672. https://doi.org/10.26719/2015.21.9.671

[28] Escamilla-Cejudo, J.A., Sanhueza, A. and Legetic, B. (2016) The Burden of Noncommunicable Diseases in the Americas and the Social Determinants of Health. Econ Dimens Noncommunicable Dis Lat Am Caribb. 13.

[29] Chaker, L., Falla, A., van der Lee, S.J., Muka, T., Imo, D., Jaspers, L., et al. (2015) The Global Impact of Non-Communicable Diseases on Macro-Economic Productivity: A Systematic Review. European Journal of Epidemiology, 30, 357-395. https://doi.org/10.1007/s10654-015-0026-5

[30] Vos, T. (2015) Global, Regional, and National Incidence, Prevalence, and Years Lived with Disability for 301 Acute and Chronic Diseases and Injuries in 188 Countries, 1990-2013: A Systematic Analysis for the Global Burden of Disease Study 2013. The Lancet, 386, 743-800.

[31] Alvarez-Arias, P., Huanca-Yufra, F., Caira, B., Zafra-Tanaka, J.H. and Moreno-Loaiza, O. (2019) Prevalencia de hipertensión arterial en Perú según las nuevas recomendaciones de la guía AHA 2017: Análisis secundario de Endes 2016. Salud Pública de México, 61, 98-99. https://doi.org/10.21149/9542 